\title{
Genetic association between interluekin-4 rs2243250 polymorphism and gastric cancer susceptibility: evidence based on a meta-analysis
}

This article was published in the following Dove Press journal:

OncoTargets and Therapy

20 April 2016

Number of times this article has been viewed

\author{
Chi Zhangl,* \\ Jing-Yu Huang ${ }^{1, *}$ \\ $\mathrm{Zi}-\mathrm{Qi} \mathrm{He} \mathrm{He}^{2, *}$ \\ Hong Weng ${ }^{3}$ \\ 'Department of Oncology, Zhongnan \\ Hospital of Wuhan University, \\ Wuhan, Hubei, People's Republic \\ of China; ${ }^{2}$ Department of Urology, \\ First Affiliated Hospital of Guangxi \\ Medical University, Nanning, Guangxi, \\ People's Republic of China; ${ }^{3}$ Center \\ for Evidence-Based and Translational \\ Medicine, Zhongnan Hospital of \\ Wuhan University, Wuhan, Hubei, \\ People's Republic of China
}

*These authors contributed equally to this work
Correspondence: Hong Weng Center for Evidence-Based and Translational Medicine, Zhongnan Hospital of Wuhan University, 169 Donghu Road, Wuchang, Wuhan 43007I, Hubei, People's Republic of China

Tel +86 2767812817

Fax +862767812817

Email wengh92@163.com
Purpose: Numerous studies have suggested that the interleukin-4 (IL-4) rs2243250 polymorphism is associated with gastric cancer susceptibility. However, the results were inconsistent. Hence, we carried out a meta-analysis to confirm the conclusion.

Methods: We searched PubMed, Embase, CBM, CNKI, and Wanfang Data to identify relevant studies up to August 20, 2015. Odds ratio (OR) and 95\% confidence interval (CI) were used to estimate the association between $I L-4$ rs2243250 polymorphism and gastric cancer susceptibility. All the statistical analyses were performed with Stata 12.0 software.

Results: A total of eleven published case-control studies were identified, including 2,247 gastric cancer patients and 3,370 controls. Overall, no significant association between $I L-4$ rs2243250 polymorphism and gastric cancer susceptibility was observed in this meta-analysis ( $\mathrm{T}$ vs $\mathrm{C}: \mathrm{OR}=1.05,95 \% \mathrm{CI}=0.95-1.17$; TT vs $\mathrm{CC}: \mathrm{OR}=1.20,95 \% \mathrm{CI}=0.89-1.63$; $\mathrm{CT}$ vs CC: $\mathrm{OR}=1.14,95 \% \mathrm{CI}=0.87-1.48$; TT $+\mathrm{CT}$ vs $\mathrm{CC}: \mathrm{OR}=1.13,95 \% \mathrm{CI}=0.89-1.44$; $\mathrm{TT}$ vs $\mathrm{CT}+$ $\mathrm{CC}: \mathrm{OR}=1.02,95 \% \mathrm{CI}=0.88-1.20$ ). Similar results were found in subgroup analyses according to ethnicity and Hardy-Weinberg equilibrium in controls.

Conclusion: This meta-analysis suggests that $I L-4$ rs2243250 polymorphism may not be associated with gastric cancer susceptibility. Further studies are needed to validate this conclusion.

Keywords: interleukin-4, meta-analysis, polymorphism, genetic, stomach neoplasms

\section{Introduction}

Gastric cancer is a leading cause of death by cancer worldwide and is the fifth most common cancer. ${ }^{1}$ Gastric cancer in particular ranks as the third major malignancy in terms of mortality. Approximately 951,000 new cases of gastric cancer and 723,000 deaths were estimated worldwide in $2012 .{ }^{1}$ Gastric cancer is classified as cardia and noncardia types in anatomy, and the latter makes up the major part of the cases. Gastric cancer is a multifactorial and complex disease that involves numerous environmental and lifestyle factors, including smoking and poor diet, and Helicobacter pylori infection may increase the development of gastric cancer. ${ }^{2}$ Causes of gastric cancer are still unclear and genetic effects, especially single-nucleotide polymorphism (SNP), attract more attention to the study of gene polymorphism in relation to gastric cancer.,

Interleukin-4 (IL-4) is identified as a contributing factor to gastric carcinogenesis, and it is an indispensable element in the inflammation pathway and is considered as a basic part of the oncogenic process in gastric cancer. ${ }^{5,6} \mathrm{IL}-4$ plays a vital role in tumor immunology, differentiation of hematopoietic cell, and maturation of T-helper (Th) cells to the Th2 phenotype. $^{7} I L-4$ gene is located on chromosome 5q31-33. The $I L-4$ gene rs 2243250 polymorphism, C to T base substitution at -590 of the $I L-4$ promoter, 
increases the IL-4 expression. ${ }^{5}$ Therefore, the polymorphism may modify the intensity of the inflammatory response, which contributes to gastric cancer development. ${ }^{8}$

Numerous studies addressed the association between IL-4 rs2243250 polymorphism and risk of developing gastric cancer. In the past 2 years, two meta-analyses investigated the association. ${ }^{9,10}$ Interestingly, the conclusions of the two previous meta-analyses were contradictory. In addition, more case-control studies have been published during these past 2 years. Based on all these factors, we performed this meta-analysis to try and find a more precise result on the association between $I L-4$ rs2243250 polymorphism and risk of developing gastric cancer.

\section{Materials and methods}

\section{Literature search}

A comprehensive literature search was performed in PubMed, Embase, CBM, CNKI, and Wanfang Data up to August 20, 2015 , to retrieve studies addressing the association between $I L-4$ rs2243250 polymorphism and risk of developing gastric cancer with the following items: ([interleukin 4 OR interleukin-4 OR IL-4 OR IL4] and [gastric or stomach] and [cancer or tumor or carcinoma], and [polymorphism or mutation OR variation]). Reference lists of the included studies and recent reviews were retrieved for additional studies. No language restriction was applied in this meta-analysis.

\section{Study selection criteria}

Studies were included in this meta-analysis if they met the following criteria: 1) had a case-control design; 2) examined the association between $I L-4$ rs2243250 polymorphism and gastric cancer susceptibility; 3 ) included patients who were diagnosed with gastric cancer and controls who were cancer free; and 4) had sufficient data for calculating odds ratios (ORs) and corresponding 95\% confidence intervals (CIs). In addition, we excluded the following: 1) unpublished studies or abstracts; 2) studies in which the genotype distributions were not reported; and 3) studies in nonhuman subjects.

\section{Data extraction}

Two authors extracted the following information from the included studies: author name, publication year, country, ethnicity of the study subject, sample size, genotype distribution, and Hardy-Weinberg equilibrium (HWE) for controls. In addition, any disagreements were resolved by discussion.

\section{Statistical analysis}

The $\chi^{2}$ test was used to examine whether the genotype frequencies in controls were consistent with HWE. The ORs and corresponding $95 \%$ CIs were calculated to assess the strength of association between IL-4 rs2243250 polymorphism and gastric cancer susceptibility using the following five genetic models: allelic contrast ( $\mathrm{T}$ vs C), homozygote contrast (TT vs CC), heterozygote contrast (CT vs CC), dominant model $\left(\mathrm{TT}+\mathrm{CT}\right.$ vs CC), and recessive model (TT vs CT + CC). ${ }^{5,11-13}$ Heterogeneity was detected using the $Q$-test and $I^{2}$ statistic. ${ }^{14}$ The random-effects model was employed to aggregate the results of the included studies, which reduces to fixed-effects model when no between-study heterogeneity exists. Sensitivity analysis by excluding studies not in HWE in controls and subgroup analyses based on ethnicity were also performed. Publication bias was assessed by funnel plot and Egger's linear regression test to quantitatively measure the asymmetry of funnel plots. ${ }^{15}$ The $\alpha$ level of significance was set at 0.05 , except for the $Q$-test for heterogeneity $(0.1)$.

\section{Results \\ Study characteristics}

Of the 95 records retrieved initially, a total of eleven published case-control studies ${ }^{7,16-25}$ were ultimately identified involving 2,247 gastric cancer patients and 3,370 controls. Figure 1 shows the detailed flowchart of the study selection process. Table 1 lists the main characteristics of the included studies. Four studies ${ }^{7,16,19,21}$ involved Caucasian populations, and seven studies ${ }^{17,18,20,22-25}$ involved Asians. The genotype distributions of controls from five studies ${ }^{16,17,20,23,24}$ were inconsistent with HWE.

\section{Meta-analysis}

The main results of this meta-analysis are listed in Table 2. Overall, no significant relationship was observed between $I L-4$ rs2243250 polymorphism and gastric cancer susceptibility in the total populations ( $\mathrm{T}$ vs $\mathrm{C}$ : $\mathrm{OR}=1.05,95 \%$ $\mathrm{CI}=0.95-1.17$; TT vs CC: $\mathrm{OR}=1.20,95 \% \mathrm{CI}=0.89-1.63$, Figure 2; CT vs CC: $1.14,95 \% \mathrm{CI}=0.87-1.48$; TT + CT vs $\mathrm{CC}$ : $\mathrm{OR}=1.13,95 \% \mathrm{CI}=0.89-1.44$; $\mathrm{TT}$ vs $\mathrm{CT}+\mathrm{CC}$ : $\mathrm{OR}=1.02,95 \% \mathrm{CI}=0.88-1.20)$. Similarly, in the succeeding sensitivity analysis by excluding studies not in HWE in controls, no significant association was found between $I L-4$ rs2243250 polymorphism and gastric cancer susceptibility in the total populations (Table 2). Finally, even in the stratified analysis by ethnicity, we did not observe any significant association between $I L-4$ rs2243250 polymorphism and gastric cancer susceptibility (Table 2).

\section{Publication bias}

Begg's funnel plot seemed symmetric for all five genetic models. Figure 3 shows the shapes of the funnel plots of 


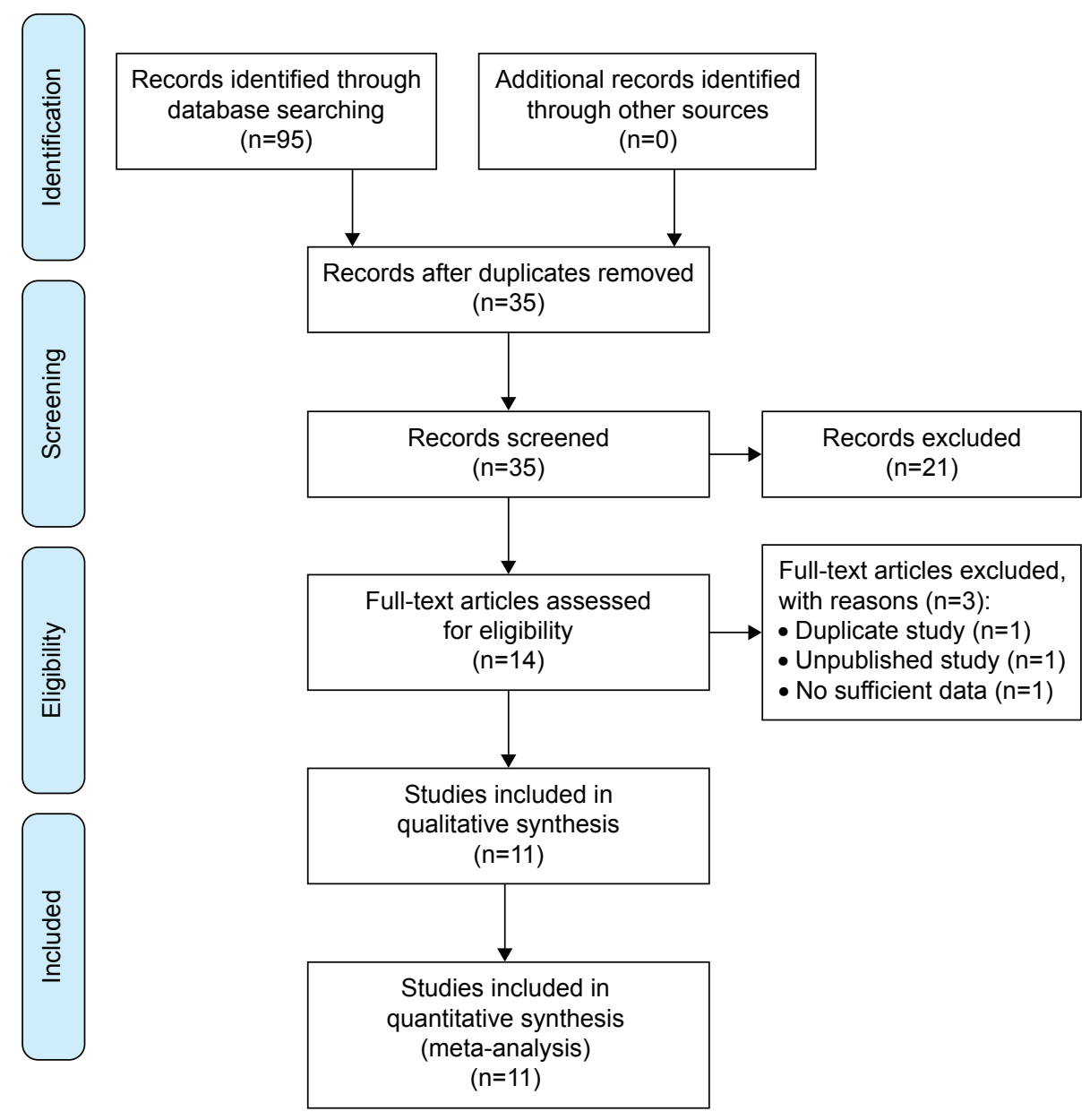

Figure I Flowchart of the study selection.

homozygote contrast used in the studies for examining all populations. The result was further supported by Egger's tests. No evidence of publication bias was detected in this meta-analysis $(P=0.57$ for T vs $\mathrm{C} ; P=49$ for TT vs $\mathrm{CC} ; P=0.94$ for $\mathrm{CT}$ vs $\mathrm{CC} ; P=0.60$ for TT $+\mathrm{CT}$ vs $\mathrm{CC} ; P=0.65$ for TT vs CT + CC; Table 2).

\section{Discussion}

Nowadays, genetic susceptibility in cancer development, especially SNPs, has drawn a great attention to the research of gene variation involved in carcinogenesis. ${ }^{26,27}$ Gastric cancer is a multifactorial and complicated disease in which gene effects have been considered as a predominant component.

Table I Characteristics of included studies in the meta-analysis

\begin{tabular}{|c|c|c|c|c|c|c|c|c|c|c|}
\hline \multirow[t]{2}{*}{ Study } & \multirow[t]{2}{*}{ Country } & \multirow[t]{2}{*}{ Ethnicity } & \multirow{2}{*}{$\begin{array}{l}\text { Sample size } \\
\text { (case/control) }\end{array}$} & \multicolumn{3}{|c|}{ Cases } & \multirow{2}{*}{$\begin{array}{l}\text { HWE in } \\
\text { controls }\end{array}$} & \multicolumn{3}{|c|}{ Controls } \\
\hline & & & & $\overline{C C}$ & CT & TT & & $\overline{C C}$ & CT & TT \\
\hline El-Omar et al ${ }^{16}$ & America & Caucasian & $314 / 210$ & 78 & 37 & 7 & 0.013 & 153 & 46 & 10 \\
\hline Wu et $\mathrm{al}^{17}$ & People's Republic of China & Asian & $220 / 230$ & 5 & 69 & 146 & 0.016 & 12 & 55 & 163 \\
\hline Lai et $\mathrm{al}^{18}$ & People's Republic of China & Asian & $123 / 162$ & 2 & 38 & 83 & 0.737 & 7 & 50 & 105 \\
\hline Garcia-Gonzalez et al ${ }^{19}$ & Spain & Caucasian & $404 / 404$ & 283 & 107 & 14 & 0.971 & 267 & 123 & 14 \\
\hline Crusius et $\mathrm{al}^{7}$ & Europe & Caucasian & $242 / 1,154$ & 159 & 76 & 7 & 0.603 & 824 & 305 & 25 \\
\hline Jia et $a^{20}$ & People's Republic of China & Asian & $106 / 108$ & 3 & 35 & 68 & 0.010 & 0 & 43 & 65 \\
\hline Zambon et $\mathrm{al}^{21}$ & Italy & Caucasian & $40 / 64$ & 32 & 7 & 1 & 0.800 & 45 & 17 & 2 \\
\hline Ando et $\mathrm{a}^{22}$ & Japan & Asian & $330 / 190$ & 26 & 158 & 146 & 0.248 & 18 & 92 & 80 \\
\hline Ko et $\mathrm{a}^{23}$ & Korea & Asian & $84 / 336$ & 4 & 24 & 53 & 0.019 & 22 & 95 & 207 \\
\hline Long et $\mathrm{a}^{24}$ & People's Republic of China & Asian & $112 / 238$ & 6 & 28 & 78 & 0.028 & 10 & 53 & 175 \\
\hline Pan et $\mathrm{al}^{25}$ & People's Republic of China & Asian & $275 / 274$ & 9 & 85 & $|8|$ & 0.383 & 8 & 90 & 176 \\
\hline
\end{tabular}

Abbreviation: HWE, Hardy-Weinberg equilibrium. 
Table 2 Meta-analysis of the association between IL-4 rs2243250 polymorphism and gastric cancer

\begin{tabular}{|c|c|c|c|c|c|c|c|}
\hline \multirow[t]{2}{*}{ Analysis } & \multirow[t]{2}{*}{ Number of studies } & \multicolumn{3}{|c|}{ Test of association } & \multicolumn{2}{|c|}{ Heterogeneity } & \multirow{2}{*}{$\begin{array}{l}P \text {-value for } \\
\text { Egger's test }\end{array}$} \\
\hline & & OR & $95 \% \mathrm{Cl}$ & $P$-value & $I^{2}$ & $P$-value & \\
\hline \multicolumn{8}{|l|}{ T vs C } \\
\hline Overall & 11 & 1.05 & $0.95-1.17$ & 0.34 & 0.0 & 0.51 & 0.57 \\
\hline HWE (yes) & 6 & 1.05 & $0.92-1.21$ & 0.44 & 11.0 & 0.35 & \\
\hline Caucasian & 4 & 1.08 & $0.81-1.42$ & 0.61 & 57.9 & 0.07 & \\
\hline Asian & 7 & 1.03 & $0.90-1.18$ & 0.63 & 0.0 & 0.93 & \\
\hline \multicolumn{8}{|l|}{ TT vs CC } \\
\hline Overall & 11 & 1.20 & $0.89-1.63$ & 0.24 & 0.0 & 0.81 & 0.49 \\
\hline HWE (yes) & 6 & 1.19 & $0.8 \mathrm{I}-1.73$ & 0.38 & 0.0 & 0.83 & \\
\hline Caucasian & 4 & 1.17 & $0.72-1.90$ & 0.53 & 0.0 & 0.85 & \\
\hline Asian & 7 & 1.22 & $0.83-1.81$ & 0.31 & 0.0 & 0.51 & \\
\hline \multicolumn{8}{|l|}{ CT vs CC } \\
\hline Overall & 11 & 1.14 & $0.87-1.48$ & 0.34 & 34.2 & 0.13 & 0.94 \\
\hline HWE (yes) & 6 & 1.02 & $0.78-1.35$ & 0.87 & 30.3 & 0.21 & \\
\hline Caucasian & 4 & 1.07 & $0.75-1.54$ & 0.70 & 62.5 & 0.05 & \\
\hline Asian & 7 & 1.26 & $0.8 \mathrm{I}-1.95$ & 0.30 & 10.9 & 0.35 & \\
\hline \multicolumn{8}{|c|}{$\mathrm{TT}+\mathrm{CT}$ vs $\mathrm{CC}$} \\
\hline Overall & 11 & 1.13 & $0.89-1.44$ & 0.33 & 30.0 & 0.16 & 0.60 \\
\hline HWE (yes) & 6 & 1.04 & $0.79-1.37$ & 0.78 & 33.8 & 0.18 & \\
\hline Caucasian & 4 & 1.08 & $0.76-1.53$ & 0.67 & 0.04 & 63.3 & \\
\hline Asian & 7 & 1.22 & $0.83-1.80$ & 0.30 & 0.0 & 0.45 & \\
\hline \multicolumn{8}{|l|}{ TT vs $C T+C C$} \\
\hline Overall & 11 & 1.02 & $0.88-1.20$ & 0.76 & 0.0 & 0.98 & 0.65 \\
\hline HWE (yes) & 6 & 1.09 & $0.89-1.35$ & 0.40 & 0.0 & 0.99 & \\
\hline Caucasian & 4 & 1.14 & $0.70-1.84$ & 0.59 & 0.0 & 0.95 & \\
\hline Asian & 7 & 1.01 & $0.86-1.19$ & 0.89 & 0.0 & 0.85 & \\
\hline
\end{tabular}

Abbreviations: $\mathrm{Cl}$, confidence interval; $\mathrm{HWE}$, Hardy-Weinberg equilibrium; OR, odds ratio.

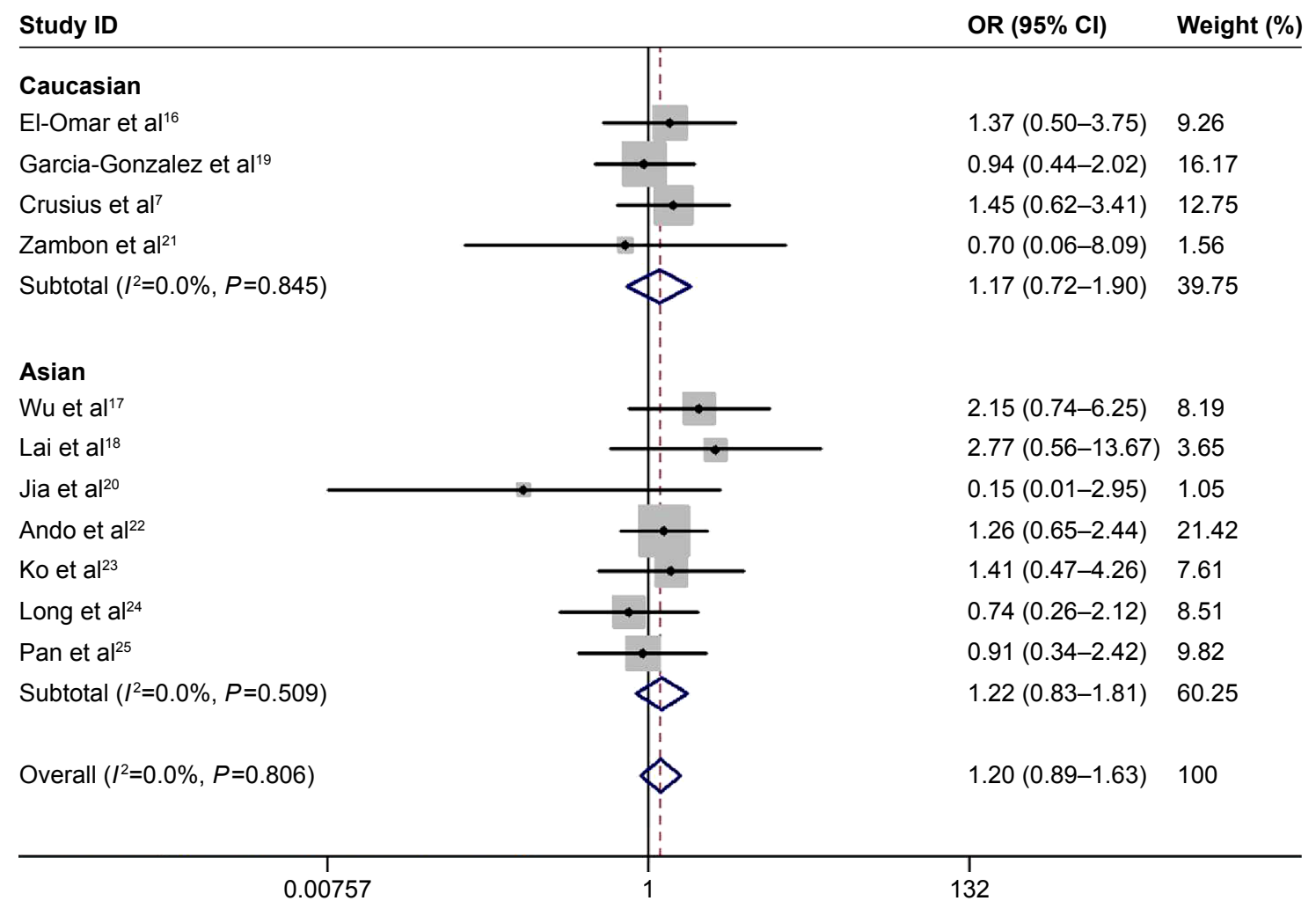

Figure 2 Forest plots of the meta-analysis for TT vs CC genetic model.

Note: Weights are from random-effects analysis.

Abbreviations: $\mathrm{Cl}$, confidence interval; $\mathrm{OR}$, odds ratio. 


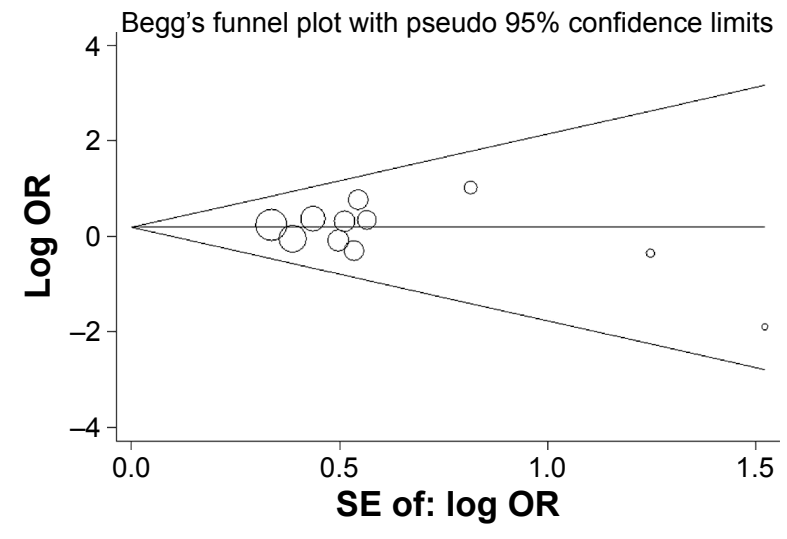

Figure 3 Begg's funnel plot of the TT vs CC genetic model. Abbreviations: SE, standard error; OR, odds ratio.

With the development of molecular epidemiology, numerous studies addressed the effects of $I L-4$ rs 2243250 polymorphism on gastric cancer susceptibility. In 2003, El-Omar et $\mathrm{a}^{16}$ investigated the proinflammatory cytokine gene polymorphism on the risk of noncardia gastric cancer and indicated that $I L-4$ was not associated with any of the cancers studied. However, subsequent studies did not reveal similar results, ${ }^{10,21}$ and the conclusion of the relationship between $I L-4$ rs 2243250 polymorphism and gastric cancer susceptibility remains controversial. This meta-analysis included eleven published case-control studies and was conducted to evaluate the true association between $I L-4$ rs2243250 polymorphism and gastric cancer susceptibility; no significant difference was observed in overall analysis. Sensitivity analysis by excluding studies not in HWE in controls and subgroup analysis according to ethnicity also showed similar results.

In 2013, Zhang et $\mathrm{al}^{9}$ performed a meta-analysis in which they investigated the $I L-4$ rs 2243250 polymorphism and risk of cancer and suggested that the $I L-4$ rs2243250 polymorphism was not associated with increased/decreased risk of cancer. In their work, they identified eight casecontrol studies evaluating the association between the $I L-4$ rs2243250 polymorphism and risk of gastric cancer, two of which were unpublished master thesis in the People's Republic of China. ${ }^{9}$ As we all know, the unpublished studies were not evaluated by peer review, and more biases would be incurred if they were included in the meta-analysis. In 2014, Sun et a ${ }^{10}$ carried out a meta-analysis to investigate the association between $I L-4$ rs 2243250 polymorphism and risk of gastric cancer with only seven case-control studies and suggested that $I L-4$ rs2243250 polymorphism was associated with a lower gastric cancer risk under dominant model and allelic model in Caucasian. With respect to the aforementioned controversial results, we performed this meta-analysis with the most compressively literature search and excluded the unpublished studies.

\section{Limitations}

Like any meta-analysis study, this meta-analysis also has some limitations that should be taken into consideration. ${ }^{28-31}$ First, these results are based on unadjusted estimates, which would be biased by other factors, such as other genes and environment. ${ }^{32}$ Second, the sample size of this study is relatively small. Therefore, the statistical power to investigate the true association between $I L-4$ rs 2243250 polymorphism and gastric cancer susceptibility is relatively low, and the evidence in this meta-analysis might be less powerful. Third, even though we did not detect any evidence of between-study heterogeneity in the total population, we observed moderateto-substantial between-study heterogeneity for Caucasians in allele contrast and heterozygote contrast models. This heterogeneity might be derived from the genotyping method, type of disease, and/or diverse environmental circumstances. ${ }^{5,33}$ Furthermore, we did not perform stratification analysis according to disease type (cardia and noncardia) due to insufficient original data. In spite of these limitations, this study currently is the best available evidence with a more comprehensive literature search and no publication bias, as compared with the previous meta-analyses.

\section{Conclusion}

Despite these limitations, our meta-analysis indicated that IL-4 rs2243250 polymorphism may not be associated with gastric cancer susceptibility. Further large-scale and welldesigned studies are necessary to validate this conclusion.

\section{Disclosure}

The authors report no conflicts of interest in this work.

\section{References}

1. Ferlay J, Soerjomataram I, Dikshit R, et al. Cancer incidence and mortality worldwide: sources, methods and major patterns in GLOBOCAN 2012. Int J Cancer. 2015;136(5):E359-E386.

2. Crew KD, Neugut AI. Epidemiology of gastric cancer. World J Gastroenterol. 2006;12(3):354-362.

3. Zeng SB, Weng H, Zhou M, Duan XL, Shen XF, Zeng XT. Long-term coffee consumption and risk of gastric cancer: a PRISMA-compliant dose-response meta-analysis of prospective Cohort studies. Medicine (Baltimore). 2015;94(38):e1640.

4. Song B, Yan G, Hao H, Yang B. rs11671784 G/A and rs895819 A/G polymorphisms inversely affect gastric cancer susceptibility and miR-27a expression in a Chinese population. Med Sci Monit. 2014;20:2318-2326.

5. Yan Y, Weng H, Shen ZH, Wu L, Zeng XT. Association between interleukin-4 gene $-590 \mathrm{c} / \mathrm{t},-33 \mathrm{c} / \mathrm{t}$, and 70-base-pair polymorphisms and periodontitis susceptibility: a meta-analysis. J Periodontol. 2014; 85(11):e354-e362.

6. Thun MJ, DeLancey JO, Center MM, Jemal A, Ward EM. The global burden of cancer: priorities for prevention. Carcinogenesis. 2010;31(1): 100-110. 
7. Crusius JB, Canzian F, Capella G, et al. Cytokine gene polymorphisms and the risk of adenocarcinoma of the stomach in the European prospective investigation into cancer and nutrition (EPIC-EURGAST). Ann Oncol. 2008;19(11):1894-1902.

8. Gonzalez CA, Sala N, Capella G. Genetic susceptibility and gastric cancer risk. Int $J$ Cancer. 2002;100(3):249-260.

9. Zhang J, Xie D, Zhou H, et al. The $-590 \mathrm{C} / \mathrm{T}$ polymorphism in the IL-4 gene and the risk of cancer: a meta-analysis. Tumour Biol. 2013; 34(4):2261-2268.

10. Sun Z, Cui Y, Jin X, Pei J. Association between IL-4 -590C > T polymorphism and gastric cancer risk. Tumour Biol. 2014;35(2):1517-1521.

11. Jiang L, Weng H, Chen MY, Zhang C, Zeng XT. Association between cyclooxygenase-2 gene polymorphisms and risk of periodontitis: a meta-analysis involving 5653 individuals. Mol Biol Rep. 2014;41(7): 4795-4801.

12. Zeng XT, Lu JT, Tang XJ, Weng H, Luo J. Association of methionine synthase rs1801394 and methionine synthase reductase rs1805087 polymorphisms with meningioma in adults: a meta-analysis. Biomed Rep. 2014;2(3):432-436.

13. Zeng XT, Yao QS, Weng H, Li S, Huang JY, Wang XH. Meta-analysis of vitamin D receptor gene polymorphisms and benign prostatic hyperplasia risk. Mol Biol Rep. 2014;41(10):6713-6717.

14. Higgins JP, Thompson SG. Quantifying heterogeneity in a metaanalysis. Stat Med. 2002;21(11):1539-1558.

15. Egger M, Davey Smith G, Schneider M, Minder C. Bias in meta-analysis detected by a simple, graphical test. BMJ. 1997;315(7109):629-634.

16. El-Omar EM, Rabkin CS, Gammon MD, et al. Increased risk of noncardia gastric cancer associated with proinflammatory cytokine gene polymorphisms. Gastroenterology. 2003;124(5):1193-1201.

17. Wu MS, Wu CY, Chen CJ, Lin MT, Shun CT, Lin JT. Interleukin-10 genotypes associate with the risk of gastric carcinoma in Taiwanese Chinese. Int J Cancer. 2003;104(5):617-623.

18. Lai KC, Chen WC, Jeng LB, Li SY, Chou MC, Tsai FJ. Association of genetic polymorphisms of MK, IL-4, p16, p21, p53 genes and human gastric cancer in Taiwan. Eur J Surg Oncol. 2005;31(10):1135-1140.

19. Garcia-Gonzalez MA, Lanas A, Quintero E, et al. Gastric cancer susceptibility is not linked to pro-and anti-inflammatory cytokine gene polymorphisms in whites: a Nationwide Multicenter Study in Spain. Am J Gastroenterol. 2007;102(9):1878-1892.

20. Jia A, Gong J, Li YC, Hao ZM, Chang XM, Dong L. Correlation between polymorphisms of IL-4, tumor necrosis factor $\alpha$ gene and noncardiac gastric cancer in Han people of Shaanxi province. Wei Chang Bing Xue He Gan Bing Xue Za Zhi. 2008;17(8):642-644. Chinese.

21. Zambon CF, Basso D, Marchet A, et al. IL-4 -588C $>$ T polymorphism and IL-4 receptor $\alpha($ Ex5+14A $>$ G; Ex11+828A $>$ G) haplotype concur in selecting H. pylori cagA subtype infections. Clin Chim Acta. 2008; 389(1-2):139-145.
22. Ando T, Ishikawa T, Kato H, et al. Synergistic effect of HLA class II loci and cytokine gene polymorphisms on the risk of gastric cancer in Japanese patients with Helicobacter pylori infection. Int J Cancer. 2009; 125(11):2595-2602.

23. Ko KP, Park SK, Cho LY, et al. Soybean product intake modifies the association between interleukin-10 genetic polymorphisms and gastric cancer risk. J Nutr. 2009;139(5):1008-1012.

24. Long HH, Liang XL, Hu HB, Liu ZP, Chen CL. Correlation of IL-4 gene polymorphisms with Helicobacter pylori infection and susceptibility of gastric cancer. Zhongguo Re Dai Yi Xue. 2013;13(4):427-429. Chinese.

25. Pan XF, Wen Y, Loh M, et al. Interleukin-4 and -8 gene polymorphisms and risk of gastric cancer in a population in Southwestern China. Asian Pac J Cancer Prev. 2014;15(7):2951-2957.

26. Leng WD, He MN, Chen QL, Gong H, Zhang L, Zeng XT. Vascular endothelial growth factor (VEGF) gene polymorphisms and risk of head and neck cancer: a meta-analysis involving 2,444 individuals. Mol Biol Rep. 2013;40(10):5987-5992.

27. Zeng XT, Luo W, Geng PL, Guo Y, Niu YM, Leng WD. Association between the TP53 codon 72 polymorphism and risk of oral squamous cell carcinoma in Asians: a meta-analysis. BMC Cancer. 2014; 14:469.

28. Niu YM, Weng H, Zhang C, et al. Systematic review by multivariate meta-analyses on the possible role of tumor necrosis factor- $\alpha$ gene polymorphisms in association with ischemic stroke. Neuromolecular Med. 2015;17(4):373-384.

29. Li SY, Ye JY, Liang EY, Zhou LX, Yang M. Association between MTHFR C677T polymorphism and risk of acute lymphoblastic leukemia: a metaanalysis based on 51 case-control studies. Med Sci Monit. 2015;21: 740-748.

30. Zhang M, Huang J, Tan X, et al. Common polymorphisms in the NFKBIA gene and cancer susceptibility: a meta-analysis. Med Sci Monit. 2015; 21:3186-3196.

31. Zhang M, Tan X, Huang J, et al. Association of 3 common polymorphisms of IL-27 Gene with susceptibility to cancer in Chinese: evidence from an updated meta-analysis of 27 studies. Med Sci Monit. 2015; 21:2505-2513.

32. Ruan XL, Li S, Geng P, et al. Association between TP53 Gene Codon 72 polymorphism and acute myeloid leukemia susceptibility: evidence based on a meta-analysis. Med Sci Monit. 2015;21:3048-3053.

33. Zeng XT, Liu DY, Kwong JS, Leng WD, Xia LY, Mao M. Metaanalysis of association between interleukin-1 $\beta$ C-511T polymorphism and chronic periodontitis susceptibility. J Periodontol. 2015;86(6): 812-819.
OncoTargets and Therapy

\section{Publish your work in this journal}

OncoTargets and Therapy is an international, peer-reviewed, open access journal focusing on the pathological basis of all cancers, potential targets for therapy and treatment protocols employed to improve the management of cancer patients. The journal also focuses on the impact of management programs and new therapeutic agents and protocols on

\section{Dovepress}

patient perspectives such as quality of life, adherence and satisfaction. The manuscript management system is completely online and includes a very quick and fair peer-review system, which is all easy to use. Visit http://www.dovepress.com/testimonials.php to read real quotes from published authors. 